\title{
Morphological and molecular characterization of Onchocerca fasciata (Nematoda, Onchocercidae) from dromedary camels (Camelus dromedarius) in Iran
}

\author{
Mohammad Mirzaei ${ }^{1}$, Younes Ghahvei ${ }^{1}$, Emilie Lefoulon ${ }^{2}$, Riccardo Paolo Lia ${ }^{3}$, Domenico Otranto ${ }^{3}$, \\ Coralie Martin ${ }^{4, *}$, and Alireza Sazmand ${ }^{5, *}$ \\ ${ }^{1}$ Department of Pathobiology, Faculty of Veterinary Medicine, Shahid Bahonar University of Kerman, \\ Postal code: 7616914111 Kerman, Iran \\ ${ }^{2}$ Genome Biology Division, New England Biolabs, Inc., 240 County Rd, Ipswich, MA 01938, USA \\ 3 Dipartimento di Medicina Veterinaria, Università degli Studi di Bari, Str. prov. per Casamassima km 3, 70010 Valenzano, Bari, Italy \\ ${ }^{4}$ Unité Molécules de Communication et Adaptation des Microorganismes, Muséum national d'Histoire naturelle, CNRS, 75231 Paris \\ cedex 05, France \\ 5 Department of Pathobiology, Faculty of Veterinary Science, Bu-Ali Sina University, Postal code: 6517658978 Hamedan, Iran
}

Received 20 December 2017, Accepted 3 August 2018, Published online 20 September 2018

\begin{abstract}
Skin nodules of Onchocerca fasciata Railliet and Henry, 1910 (Spirurida, Onchocercidae) are a common finding in dromedary camels, though with a minimal clinical impact. There is little information about the morphology, molecular make-up and pathological impact of this parasite. Onchocerca fasciata nodules $(1.3-2.1 \mathrm{~cm}$ in diameter and $509-841 \mathrm{mg}$ in weight) were detected on the neck region in $31.5 \%$ of dromedary camels examined in Kerman province, southeastern Iran. Of 38 isolated nodules, only $23(60.5 \%)$ contained viable worms. Measurement and morphological analyses were performed on isolated female worms by light microscopy. The identification of $O$. fasciata specimens was confirmed by sequence analysis of two mitochondrial genes (12S rDNA and cox1), which showed $0.4 \%$ divergence from available $O$. fasciata sequences. In addition, a phylogeny of filarial nematodes was constructed, based on these two mitochondrial genes and five nuclear genes (18S rDNA, 28S rDNA, MyoHC, rbp1, hsp 70); this indicated that $O$. fasciata belongs to clade ONC3 of Onchocercidae, with representatives of the genera Onchocerca and Dirofilaria. Within the genus Onchocerca, O. fasciata is grouped with bovine parasitic species and the human parasitic Onchocerca volvulus, which suggests an impact of domestication on the radiation of the genus. Data provided here on the distribution and morphology of $O$. fasciata contribute to the molecular identification and phylogenetic position of the species.
\end{abstract}

Key words: Onchocerca fasciata, Vector-borne disease, Light microscopy, Phylogeny, dromedary.

\begin{abstract}
Résumé - Caractérisation morphologique et moléculaire d'Onchocerca fasciata (Nematoda, Onchocercidae) de dromadaires (Camelus dromedarius) en Iran. Les nodules cutanés d'Onchocerca fasciata Railliet and Henry, 1910 (Spirurida, Onchocercidae) sont fréquents chez les dromadaires, mais avec un impact clinique minime. Les informations sur la morphologie, la composition moléculaire et l'impact pathologique de ce parasite sont limitées. Des nodules d'O. fasciata $(1.3-2.1 \mathrm{~cm}$ de diamètre pour un poids de $509-841 \mathrm{mg})$ ont été détectés dans le cou de $31.5 \%$ des chameaux examinés dans la province de Kerman, en Iran. Sur 38 nodules isolés, seulement $23(60.5 \%)$ contenaient des vers viables. Des analyses morphologiques et des mesures ont été effectuées par microscopie optique sur des vers femelles isolées. L'identification des spécimens d'O. fasciata a été confirmée par l'analyse de deux gènes mitochondriaux ( $\mathrm{ADNr} 12 \mathrm{~S}$ et coxl) présentant une divergence de $0.4 \%$ avec les séquences d'O. fasciata disponibles. En outre, une phylogénie des nématodes filariens a été construite sur la base de ces deux gènes mitochondriaux et de cinq gènes nucléaires (ADNr 18S, ADNr 28S, MyoHC, rbpl, hsp70). Cette analyse montre que $O$. fasciata appartient au clade ONC3 des Onchocercidae qui comprend des représentants des genres Onchocerca et Dirofilaria. Au sein du genre Onchocerca, O. fasciata est regroupé avec des espèces parasitaires bovines et le parasite humain Onchocerca volvulus, ce qui suggère un impact de la domestication sur le rayonnement du genre. Les données fournies ici sur la distribution et la morphologie de $O$. fasciata contribuent à l'identification moléculaire et la position phylogénétique de l'espèce.
\end{abstract}

\footnotetext{
*Corresponding authors: alireza_sazmand@yahoo.com;
}

Coralie.Martin@mnhn.fr

This is an Open Access article distributed under the terms of the Creative Commons Attribution License (http://creativecommons.org/licenses/by/4.0), which permits unrestricted use, distribution, and reproduction in any medium, provided the original work is properly cited. 


\section{Abbreviations}

cox 1 cytochrome oxidase subunit I;

rbp1 RNA polymerase II large subunit;

hsp70 heat shock protein;

myoHC myosin heavy chain;

PBS phosphate buffered saline solution;

ND5 NADH dehydrogenase subunits 5.

\section{Introduction}

The genus Onchocerca Diesing, 1841 (Spirurida, Onchocercidae) is one of the most studied genera of the filarial nematodes, as it includes parasite species of veterinary and medical interest such as Onchocerca volvulus (Leuckart, 1893), the causative agent of human "river blindness" in tropical regions [25]. Moreover, there is an increasing number of cases of zoonotic Onchocerca infections caused by Onchocerca gutturosa Neumann, 1910, Onchocerca cervicalis Railliet and Henry, 1910, Onchocerca reticulata Diesing, 1841, Onchocerca lupi Rodonaja, 1967, Onchocerca dewittei japonica Uni, Bain and Takaoka, 2001 and Onchocerca jakutensis Gubanov, 1964 [27, 32, 45]. Despite the occasional human cases of infection, the above species most frequently infect cattle, horses, deer, boars, dogs and cats. However, an increase in number and range of zoonotic Onchocerca infections has been observed in recent years and remains unexplained [34], in part because the information on Onchocerca species in ungulate hosts, including camels, is still scarce.

With a global population of over 28 million, dromedary camels (Camelus dromedarius) are bred as multi-purpose animals in arid and semi-arid regions worldwide [17], mainly due to their extreme resistance to harsh environmental conditions. Currently, four filarial species are known to affect dromedary camels [41], namely, Onchocerca fasciata Railliet and Henry, 1910 and Deraiophoronema evansi (Lewis, 1882) (syn: Deraiophoronema cameli Romanovitch, 1916; Dipetalonema evansi), which are specific to camels; and O. gutturosa and Onchocerca armillata Railliet and Henry, 1909, which parasitize a broad range of ruminants, including camels. Onchocerca gutturosa are usually recovered from the fascia covering the ventral surface of the lamellar parts of the nuchal ligament in dromedaries as observed in Sudan [15, 21] and Australia [20], and $O$. armillata can be isolated from the aorta of dromedaries in Nigeria [42] and Sudan [3, 21]. Onchocerca fasciata forms nodules in the subcutaneous tissue and nuchal ligament that may sometimes be misdiagnosed as tubercle granulomas, resulting in unnecessary discarding of carcasses [12]. No treatment or specific control strategies have been suggested against $O$. fasciata infection. Conversely, D. evansi can induce clinical illness in infected animals (e.g., pulmonary distress, orchitis, aneurysm of the spermatic cord, arteriosclerosis, heart failure, nervous impairments and even death) in camelrearing areas of the world [39].

Onchocerca fasciata infection has been reported from many countries in Asia (e.g., Iran, Saudi Arabia, Jordan) [1, 9, 41] and Africa (e.g., Egypt, Ethiopia and Kenya) [14, 26, 38]. Despite the wide geographical distribution of onchocercosis in dromedaries, the biology of this parasite has not been studied in detail, including the insect vector species. A few studies have been performed on the histochemical distribution of several hydrolytic enzymes and dehydrogenases in adult $O$. fasciata $[30,31]$ and fine structure of female specimens have been described using transmission electron microscope examination [13]. Similarly, the molecular characterization of filarial parasites of camel is scarce with only two publications including sequences of either $O$. fasciata [23] or D. evansi [40]. These phylogenies were based on only two or three mitochondrial genes and are characterized by unresolved topology, not clearly identifying relationships between the species. Recently, a larger phylogeny of filarial nematodes based on seven genes (mitochondrial and nuclear loci) was published, but neither $D$. evansi nor $O$. fasciata were included [24]. Here we present a reappraisal of the morphological and morphometric description of $O$. fasciata based on light microscopy and molecular characterization, as well as a phylogenetic analysis of filarial nematodes including $O$. fasciata.

\section{Materials and methods Ethics}

Parasites used for this study were recovered from skin nodules collected from dromedary camels in slaughterhouses in accordance with the veterinary laws of I.R. Iran.

\section{Study area, isolation of worms and microscopic analyses}

From April to May 2016, a total of 76 dromedary camels aging from 1 to 12 years and of both sexes (43 males and 33 females) were inspected for the presence of skin nodules in slaughterhouses of Kerman, southeastern Iran (30.2839 $\mathrm{N}, 57.0834^{\circ} \mathrm{E}$ ). Nodules were recovered in accordance with the veterinary laws of I.R. Iran then transferred to the Faculty of Veterinary Medicine, Shahid Bahonar University of Kerman. Extra tissues surrounding the nodules were carefully removed and nodules digested by collagenase to isolate the adult worms from the nodules [28]. Briefly, nodules were incubated in phosphate buffered saline solution (PBS) containing type I collagenase (Sigma-Aldrich, USA) at a final concentration of $2.25 \mathrm{mg} / \mathrm{mL}$ for $24-48 \mathrm{~h}$ at $37^{\circ} \mathrm{C}$. The helminth mass and tissues were then washed with tap water and placed in petri dishes. Individual entire and broken worms were isolated under a dissecting microscope, sex was determined and each worms' length was measured. Filariae were then fixed in $70 \%$ ethanol. Fixed worms were immersed in lactophenol solution to observe anatomical structures under light microscope. Mineralized worms were identified by obliteration of cuticular ridges and vertical annulations [18]. Measurements are provided as minimum-maximum, followed by mean in parentheses.

\section{Molecular procedures}

One female was used for molecular analysis and accessioned as specimen $105 \mathrm{YT}$ in the collection of the National 
Museum of Natural History of Paris (MNHN), France. Genomic DNA was extracted with the QIAamp micro kit (Qiagen, Germany), according to the manufacturer's instructions. A preliminary step of disruption for two cycles of $30 \mathrm{~s}$ each at $30 \mathrm{~Hz}$ using a TissueLyser II (Qiagen, Germany) was added. Seven partial sequences of seven genes were amplified according to Lefoulon et al. [24]: two mitochondrial genes (12S rDNA and cytochrome oxidase subunit I (cox 1$)$ ) and five nuclear genes (18S rDNA, 28S rDNA, the myosin heavy chain $(\mathrm{MyoHC})$, RNA polymerase II large subunit ( $r b p l)$, 70 kilodalton heat shock proteins ( $h s p 70)$ ). Polymerase chain reaction (PCR) products obtained were directly sequenced and the seven sequences were deposited in GenBank (http://www.ncbi.nlm.nih.gov/) under the accession numbers: MG188679 (12S rDNA), MG188678 (cox1), MG188681 (18S rDNA), MG188680 (28S rDNA), MG188684 (MyoHC), MG188683 (rbpl), and MG188682 (hsp70).

\section{Molecular identification and phylogenetic analysis}

Two out of the seven sequenced genes were previously used for molecular identification: $12 \mathrm{~S}$ rDNA and cox 1 markers [16]. The produced sequences of $O$. fasciata and previously published sequences of Onchocerca species (Supplementary Table S1) were aligned using MAFFT [22]. The sequence divergence between Onchocerca species was estimated by the number of base differences per site between two sequences (p-distance) using MEGA5 [43].

Sequences of $O$. fasciata generated and previously published sequences (Supplementary Table S2) were independently aligned, trimmed and then concatenated. Two matrices were produced: a first matrix including all filarial nematodes and two outgroups to root the tree, Filaria latala Chabaud and Mohammad, 1989 (Spirurida, Filariidae) and Protospirura muricola Gedoelst, 1916 (Spirurida, Spiruridae); a second matrix including only Onchocerca species (Supplementary Table S3) was produced with Dirofilaria species as the outgroup to root the tree. JModelTest analysis [35] was performed to establish the evolution model best adapted to the sequence alignment for each individual gene using the corrected version of the Akaike Information Criterion (AIC; Supplementary Table S4). Phylogenetic relationships between onchocercid taxa, based on the concatenated dataset, were determined by Bayesian inference using MrBayes [37]. A partitioned model was implemented to estimate evolution parameters separately for each gene. Two runs were performed using five million steps with four chains, with tree sampling every 1000 generations; the first 1250 points were discarded as burn-in and posterior probabilities were calculated from these post-burning trees.

\section{Results}

\section{Rate of infection and nodules' examination}

Twenty-four out of 76 examined dromedary camels $(31.5 \%)$ harbored single or multiple skin onchocercian nodules on the neck region. Infected camels were aged 1-7 years and were of both sexes (11 males and 13 females). Infected camels harbored mineralized-only $(n=6,25 \%)$, viable-only $(n=11$, $45.8 \%)$, or mixed nodules $(n=7,29.2 \%)$. From 38 isolated nodules, 23 contained viable worms $(60.5 \%)$. The size of mineralized and viable nodules was $1.5-2.1(1.85) \mathrm{cm}$ and $1.3-2$ $(1.52) \mathrm{cm}$, respectively. Weight of mineralized and viable nodules was 609-841 (755) $\mathrm{mg}$ and 509-822 (607) mg.

\section{Morphological description of female and microfilariae of Onchocerca fasciata}

Twenty female worms were recovered from nodules, but no males were recovered.

Females: 3 complete, 16 with one extremity only, 1 without extremities. Anterior end rounded, mouth orifice minute (Fig. 1A). Long muscular and glandular esophagus length 1940-2100 (2020) $\mu \mathrm{m}$, width 102-104 (103) $\mu \mathrm{m}$ at the esophagus-intestinal junction level. Nerve ring at 212-230 (221) $\mu \mathrm{m}$ from the apex (Fig. 1A). Vulva 680-712 (696) $\mu \mathrm{m}$ from apex (Fig. 1B). Female body length 63-117 (90) cm, width 176-210 (196) $\mu \mathrm{m}$ at the esophagus-intestinal junction level (Fig. 1C). Cuticle 24-31 $\mu \mathrm{m}$ thick with two distinct layers (Fig. 1D). Presence of transverse external ridges (43 $\mu \mathrm{m}$ distant from each other at mid-body) and internal striae $(21 \mu \mathrm{m}$ between two striae at mid-body). Caudal end ventrally curved (Fig. 2A and Fig. 2B). Tail length 238-258 (248) $\mu \mathrm{m}$ (Fig. 2C).

Microfilariae from uteri (10 analyzed): body length 241-257 (251) $\mu \mathrm{m}$, width 3.1-3.5 (3.3) $\mu \mathrm{m}$; no sheath; blunt head; fine pointed tail (Fig. 2D).

\section{Molecular identification and phylogenetic analysis}

The cox 1 nucleotide mean divergence between the $O$. fasciata sequence and other Onchocerca sequences was 9.4\% (minimum: 5.5\% with O. gutturosa AJ271617; maximum: $12.2 \%$ with $O$. ramachandrini Bain, Wahl and Renz, 1993 KC167356) (Supplementary Table S1). The nucleotide sequence generated was $0.4 \%$ divergent from an unpublished sequence available in the NCBI database (JQ316672) indicated as belonging to $O$. fasciata species. The $12 \mathrm{~S}$ rDNA mean divergence between the $O$. fasciata sequence and other Onchocerca sequences was 5.5\% (minimum: $2 \%$ with Onchocerca sp. JX075209; maximum: $11.8 \%$ with $O$. dewittei japonica AM779816) (Supplementary Table S1). The produced sequence was $0.4 \%$ divergent from the previously published $12 \mathrm{~S}$ rDNA sequence of $O$. fasciata collected from a dromedary camel in Saudi Arabia (DQ523744) [23].

In order to facilitate the description of the tree topology, the clades will be referred to as ONC1 to ONC5, as in Lefoulon et al. [24] (Fig. 3), and letters were added for the ONC3 clade description (Fig. 4). The phylogenetic analysis based on multiple genes clusters $O$. fasciata into clade ONC3 which gather the other Onchocerca and Dirofilaria species (Fig. 3). Within the Onchocerca genus, O. fasciata forms clade ONC3A with the human parasite $O$. volvulus, $O$. lupi infecting carnivores, as well as $O$. gutturosa, O. lienalis Stiles, 1892, and $O$. ochengi 


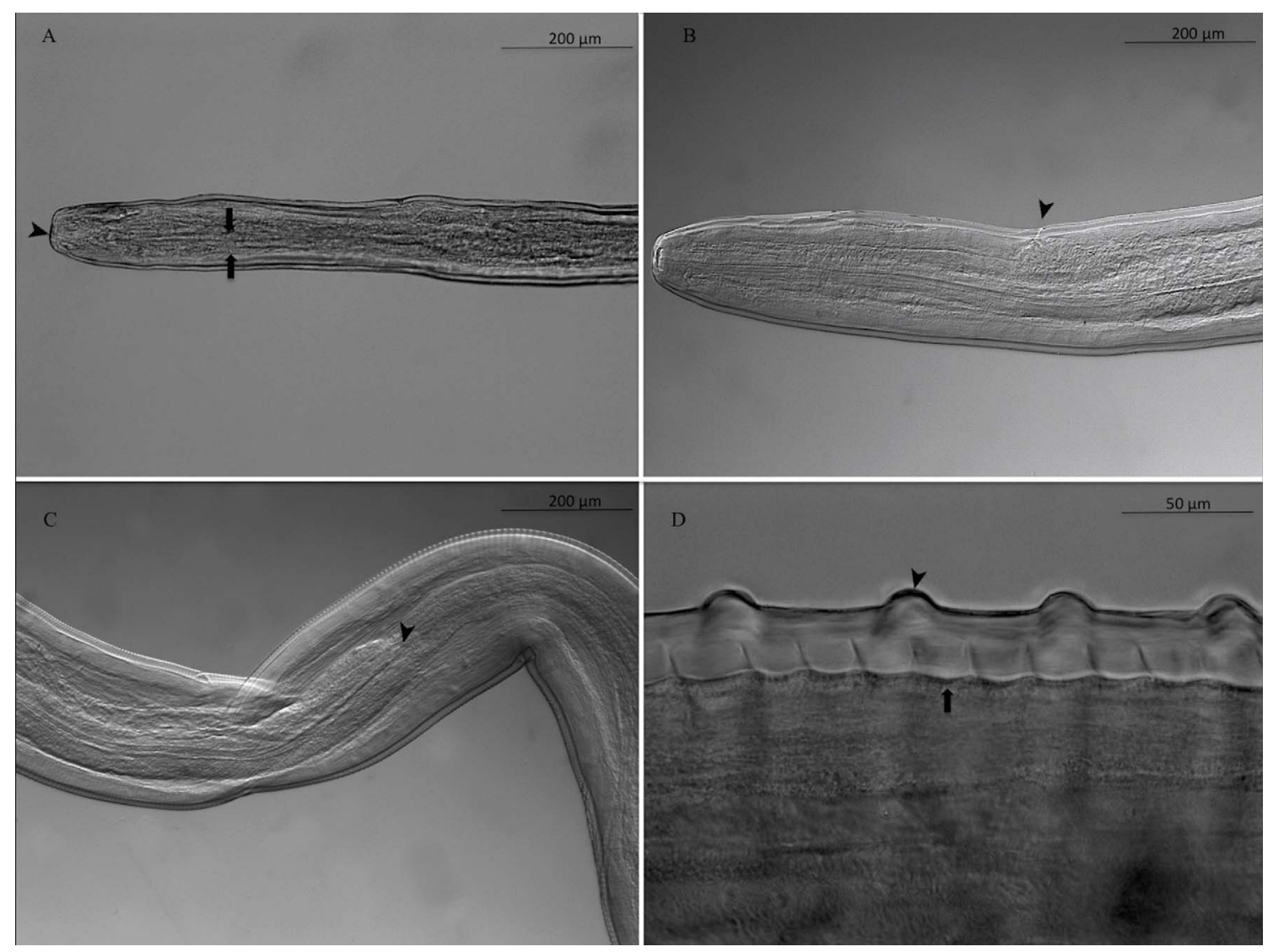

Figure 1. Adult female of Onchocerca fasciata. A. cephalic extremity in lateral view. The minute mouth orifice (arrowhead) and muscular esophagus (arrow). B. Vulvar opening (arrowhead). C. Esophago-intestinal junction (arrowhead). D. Mid-body region of the striated cuticle bearing annular transverse external ridges (arrowhead) and internal striae (arrow).

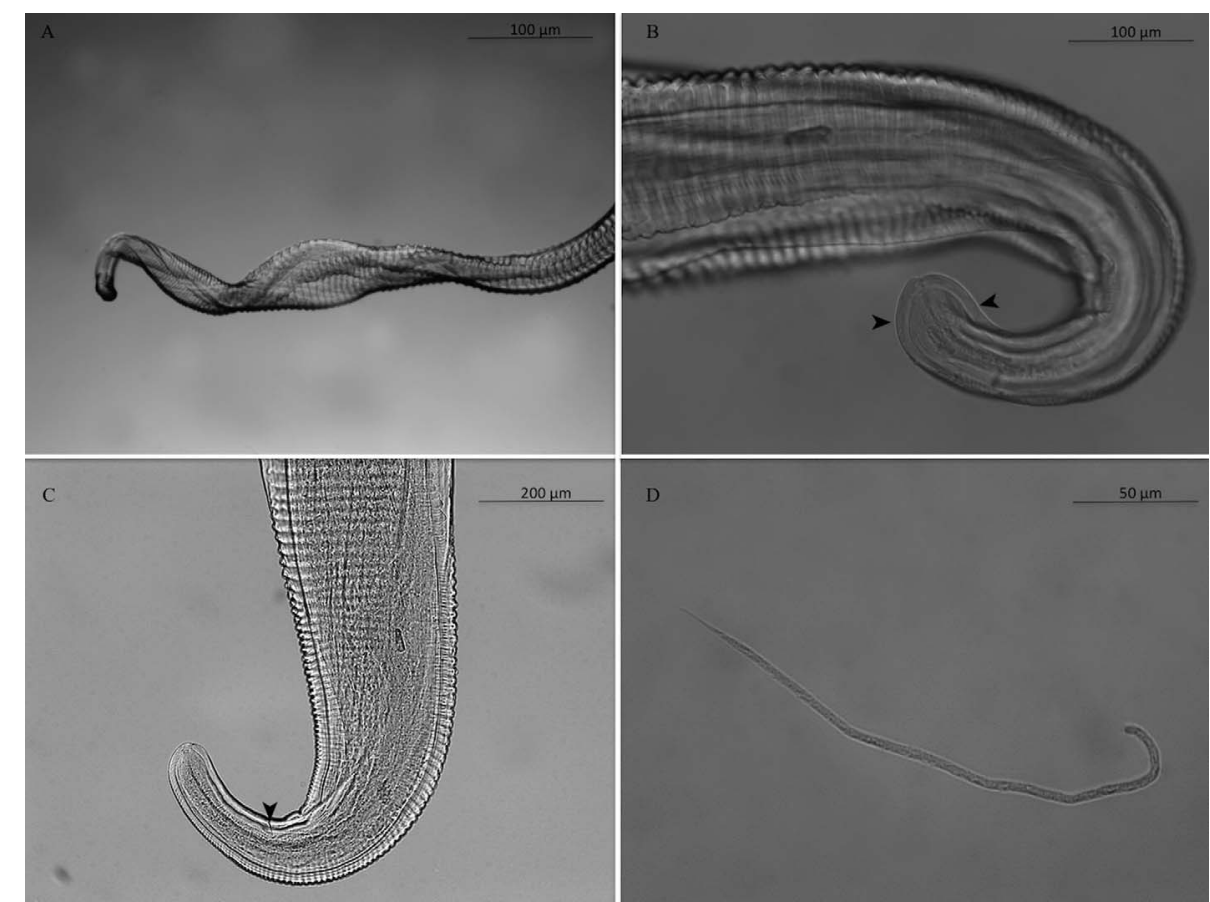

Figure 2. Adult female of Onchocerca fasciata. A. Posterior end with helicoidal twist. B. Posterior end rounded, with cuticle ridges becoming smooth (arrowhead). C. Tail, the anus (arrowhead). D. Microfilaria of $O$. fasciata isolated from the female uterus: anterior end rounded and tail pointed. 


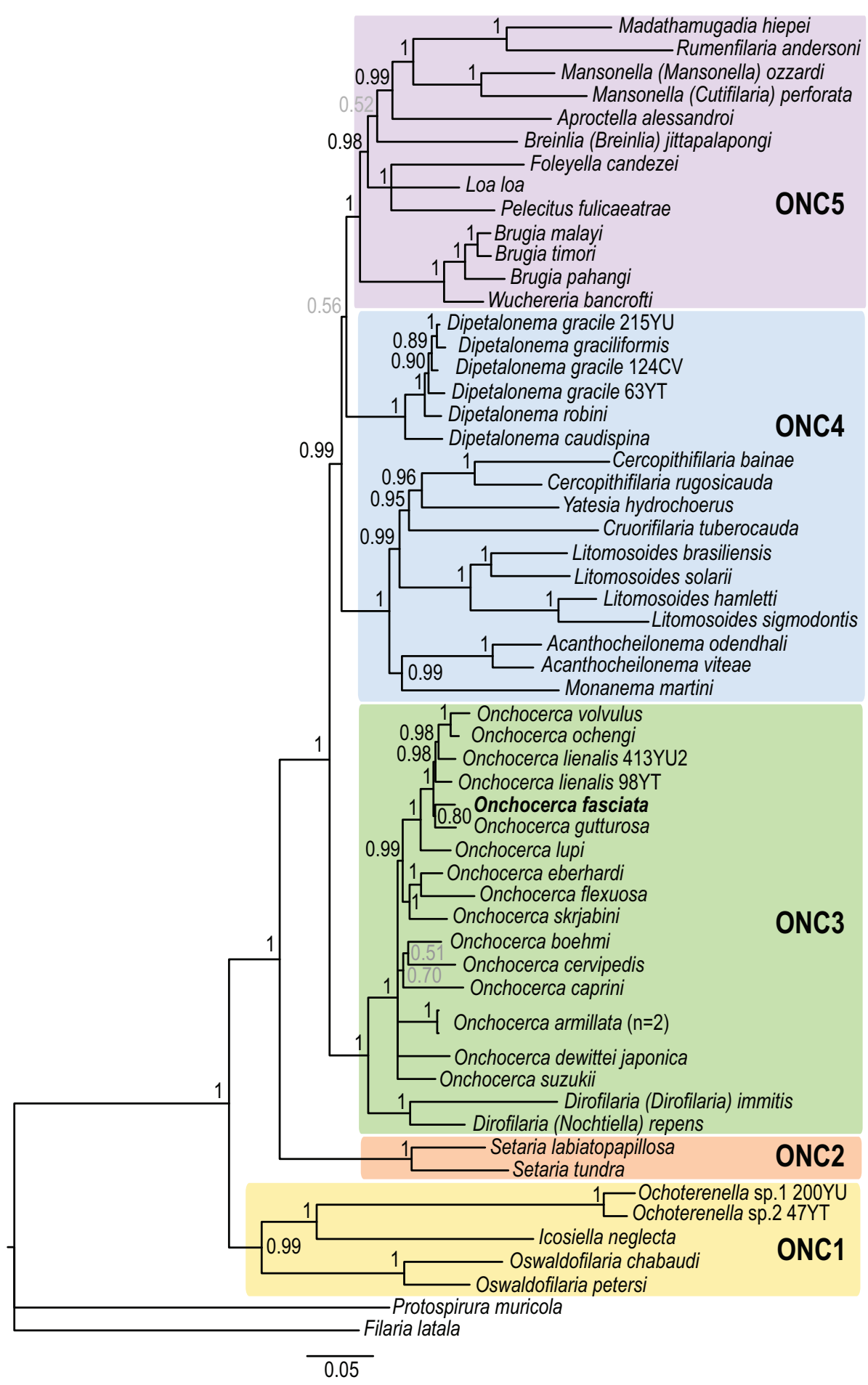

Figure 3. Phylogeny of filarial nematodes based on partitioned concatenated datasets of seven markers. Analysis is based on 12S rDNA, cytochrome oxidase subunit I (cox 1), RNA polymerase II large subunit ( $r b p 1)$, heat shock protein (hsp70), myosin heavy chain ( $m y o H C$ ), 18S rDNA and 28S rDNA sequences. Filaria latala and Protospirura muricola were used as outgroups. The topology was inferred using Bayesian inference. Nodes are associated with Bayesian posterior probabilities based on one run of five million generations. The onchocercid groups are indicated as ONC1 to ONC5 according to Lefoulon et al. [24]. Bold represents the newly sequenced specimens.

Bwangamoi, 1969 infecting cattle (Fig. 4, Supplementary Table S3). The current analysis presents $O$. fasciata as a sister taxon of $O$. gutturosa, even though the robustness of this clade associated with a posterior probability is low.

\section{Discussion}

The rate of infection in the present study (31.5\%) was in the range of that previously reported from Iran [41] and from 


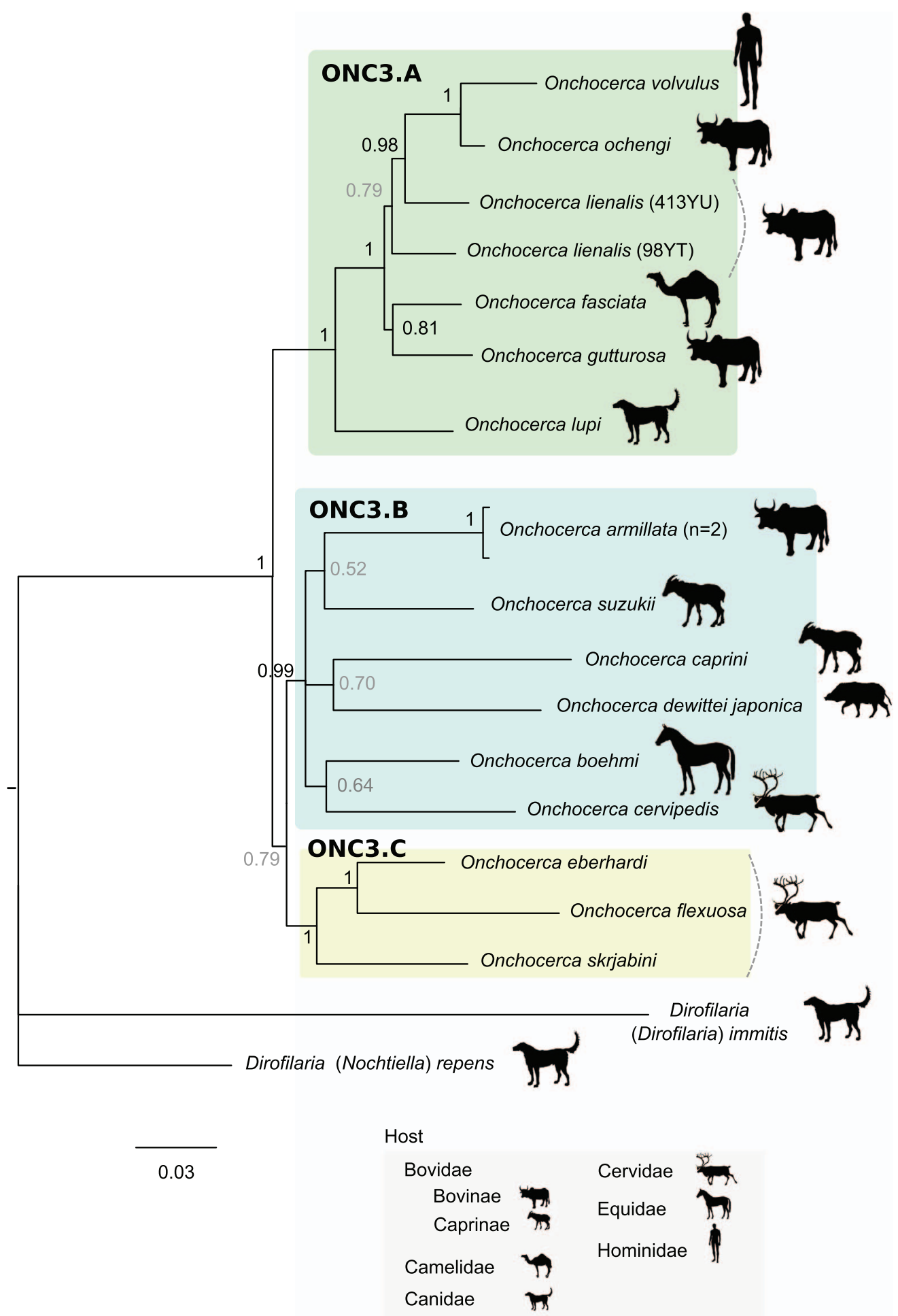

Figure 4. Phylogeny of the Onchocerca genus based on partitioned concatenated datasets of seven markers. Analysis is based on $12 \mathrm{~S}$ rDNA, cytochrome oxidase subunit I (cox1), RNA polymerase II large subunit (rbpl), heat shock protein ( $h s p 70)$, myosin heavy chain ( $m y o H C)$, 18S rDNA and 28S rDNA sequences. Dirofilaria immitis and Dirofilaria repens were used as outgroups. The topology was inferred using Bayesian inference. Nodes are associated with Bayesian posterior probabilities based on one run of five million generations. The scale bar indicates the number of nucleotide substitutions. The host vertebrate family (or subfamily) for each filarial species is indicated using the specified symbols. 
Saudi Arabia [9], but higher than that recorded in Jordan [1] (2\%) and Egypt [15] (2.6\%).

Onchocerca fasciata specimens causing nodules were studied for the first time in 1909 in two dromedary camels imported from Pakistan to Australia [19]. Nodules, in the present study, were found in subcutaneous connective tissue of the neck region. Similarly, dromedary onchocercal nodules have a fibrous capsule, are firm, not sensitive to the touch and localize mainly on the head, neck, two sides of the abdomen, shoulders, nuchal ligament, and the thigh region [2]. Histopathological examinations have revealed that multifocal granulomatous inflammatory reactions associated with the parasites are observed with thick fibrous walls, cellular infiltrate of lymphocytes, plasma cells, macrophages, multinucleated giant cells and eosinophils, associated with different degrees of coagulation necrosis and calcification around the parasites [2]. The sizes of nodules in our study varied in diameter from 1.3 to $2.1 \mathrm{~cm}$, in agreement with previous findings $[2,18]$. In particular, $O$. fasciata nodules increase with the age of dromedary camels [18] as they may contain live, degenerated or calcified worms [2]. In this study, $60.5 \%$ of worms in nodules were viable, a much higher prevalence compared to previous findings $(28 \%-34 \%$ in Saudi Arabia) $[18,29]$. A high degree of mineralization in O. fasciata compared to other Onchocerca spp. may be a likely reason for the lack of apparent disease in camels [18]. Diagnosis of camel onchocercosis is typically based on the presence of nodules and on the detection of microfilariae in skin snips. A high microfilariae concentration was noticed either in the head and neck region, or evenly distributed under the skin all over the body [11].

Morphological and morphometric characters of $O$. fasciata presented herein are consistent with those previously described [9, 11, 14]. Onchocerca fasciata was originally described in 1910 based on mid-body fragments of females, thus without extremities. The worms were recovered from a nodule extracted from the subcutaneous connective tissue of the head of a dromedary in Punjab, Pakistan [36]. Subsequent studies, from 1933 to 1938, provided morphological data on the cephalic and caudal extremities of $O$. fasciata specimens, although the description of males remained incomplete [4, 19]. Indeed, the finding of small numbers of $O$. fasciata male nematodes is most likely due to the fact that they roam in the conjunctiva and do not participate in the formation of fibrous tissues [19]. The morphological redescription of $O$. fasciata by Bain and Nasher [8] was the first to include a complete description of the male with two specimens harvested on the periphery of a nodule. This morphological analysis revealed a numerical reduction of the caudal papillae with a small grouping near the cloaca, the papillae of the head as in the infesting stage, a vulva close to the anterior extremity, and a powerful esophagus with thick glandular portion and narrow lateral chords. Female and microfilaria measurements, and morphological characters from the current study correspond to those described before $[4,8,13,36]$, clearly identifying the filariae as $O$. fasciata. The length of the esophagus in female worms in our study was $1940-2100 \mu \mathrm{m}$, within the range indicated by Bain and Nasher [8], but different from the single measure- ment of $1600 \mu \mathrm{m}$ described by Henry and Masson [19] and Badanine [4]. Females in the genus Onchocerca have specialized cuticular architecture with ridges and striae. It is more or less complex depending on the Onchocerca species. For example, transverse ridges are absent in O. suzukii Yagi, Bain and Shoho, 1994 from bovids and O. boehmi (Supperer, 1953) from equids, and the internal striae are absent in $O$. dewittei dewittei Bain, Ramachandran, Petter and Mak, 1977, O. ramachandrini, and O. dewittei japonica from suids. On the other hand, the cuticle presents 3-4 striae between adjacent transverse ridges in O. skrjabini Ruchljadev, 1964, O. garmsi Bain and Schulz-Key, 1974, O. jakutensis, O. alcis Bain and Rehbinder, 1986 and O. eberhardi Uni and Bain, 2007 from cervids. O. lupi in carnivores has 2 striae between adjoining ridges. However, some variability has also been observed in domestic bovids with $O$. gutturosa, which has 4-7 striae per inter-ridge with sinuous ridges branched in lateral fields. Regarding $O$. fasciata, our measurements are smaller than those obtained by Bain and Nasher [5], with $43 \mu \mathrm{m}$ instead of 75-80 $\mu \mathrm{m}$ measured between each ridge at mid-body of the worms. Such differences may be produced due to the development (length) of adult worms [44] and/or to a lack of precision of the mid-body position.

The molecular identification is concordant with the available sequences and published data [23, 47]. The molecular phylogeny places $O$. fasciata in the ONC3 clade of the Onchocercidae, which includes the Onchocerca and Dirofilaria species [24]. To date, only four sequences of $O$. fasciata from mitochondrial genes and one ribosomal region are available in the NCBI database: two available cox 1 and ribosomal ITS region sequences in GenBank [46, 47] and three published by Krueger and colleagues [23]. The analyses of divergence for both cox 1 and 12S rDNA sequences confirm the morphological identification. In addition, the observed high interspecific divergence validates the delineation of $O$. fasciata among the other Onchocerca species. As previously suggested, the cox 1 analysis presents better discrimination between the species $[16,25]$.

Up to now, only one molecular phylogeny based on mitochondrial genes (12S rDNA, 16S rDNA and ND5) has included $O$. fasciata [23]. The species was described either as a sister taxon of $O$. lienalis or as a sister taxon of an Onchocerca species African clade including O. volvulus, O. lienalis and $O$. dukei Bain, Bussiéras and Amégée, 1974. However, this phylogeny was characterized by multifurcated branches, indicating unresolved topology. Indeed, the evolutionary relationships between $O$. fasciata and $O$. gibsoni (Cleland and Johnston, 1910), O. gutturosa or O. jakutensis remained unclear in Krueger and colleagues [23]. Our molecular analysis presents $O$. fasciata belonging to the clade ONC3A (Figure 4) which includes $O$. lupi, $O$. gutturosa, O. lienalis, $O$. ochengi and $O$. volvulus. The analysis of nuclear genes, in addition to mitochondrial genes, is more informative, and suggests that $O$. fasciata is closely related to $O$. gutturosa although robustness of this clade remains moderate. Although $O$. gutturosa primarily infects cattle, infections in camels have also been reported $[15,20,21]$. These results contradict the evolutionary hypotheses based on morphological traits. 
Some anatomical characters, such as caudal papillae, cephalic papillae, development of esophagus, position of the vulva, and morphology of the cuticle of the female, have phyletic value for the Onchocerca genus [5, 7]. According to these characters, it was suggested that $O$. fasciata has morphological traits considered to be ancestral, such as the reduction in number and pattern of caudal papillae, an anterior position of vulva, a well-developed musculature of the female and a strongly divided oesophagus as seen in species infecting equids $O$. reticulata Diesing, 1841, O. cervicalis Railliet and Henry, 1910 and O. raillietti Bain et al., 1976 [8]. Although the latter species are not included in the sampling, the current molecular analysis suggests that $O$. fasciata species is not derived from an older independent speciation event. Nevertheless, $O$. fasciata has morphological traits that appear to be derived, such as the presence of transverse ridges in the female cuticle [8]. All Onchocerca species belonging to ONC3A clade present female cuticular architecture with ridges [25]. The structure of the female cuticle might have phyletic value for the Onchocerca genus, though larger sampling is needed to test this hypothesis.

Speciation events are influenced by multiple factors, such as host migration; thus the host distribution could be linked with Onchocerca speciation. It has previously been suggested that the emergence of the genus Onchocerca could have occurred in Africa back to the Pleistocene period with two independent speciation events, one in the forest and one from the savannah with a host switch to the human $[6,10]$. However, our current analysis does not allow us to support or reject this hypothesis because of bias in the collection of analyzed samples. For example, four species out of six in the ONC3A clade were collected in the Afrotropical region (with the exception of $O$. lupi and $O$. lienalis) but the known distribution of these species is more extended. Only $O$. ochengi is strictly limited to the Afrotropical region; $O$. volvulus has also been described in the Neotropical region; infection by $O$. gutturosa is cosmopolitan [25] and infection by $O$. fasciata has been described in the Palearctic region.

Recently, it was suggested that domestication of bovines, dogs and cats may have contributed to host-switching events that led to speciation within the clade comprising $O$. volvulus, $O$. ochengi, O. lienalis, O. gutturosa and O. lupi (mainly composed of parasites of domestic animals or humans) [21]. At least one host-switching event between domestic bovine and canid/felid hosts and one event between domestic bovine hosts and humans may have occurred. Our molecular analysis highlights that the $O$. fasciata parasite of camels belongs to this clade (ONC3A), suggesting another host-switching event between domestic bovine and camelid hosts. Domestication of dromedaries occurred between 2000-1000 years ago [33], which supports the hypothesis of a recent speciation of $O$. fasciata among the Onchocerca genus. This further supports the hypothesis that domestication may have contributed to the speciation of the genus Onchocerca.

\section{Availability of data and materials}

All data generated or analyzed during this study are included in this published article and its Additional files 1-4.

\section{Competing interests}

The authors declare that they have no competing interests.

Acknowledgements. We thank Dr Barton Slatko (native US English) for proofreading the manuscript.

\section{Funding}

A part of this study was supported financially by Shahid Bahonar University of Kerman, Iran.

\section{Author contributions}

AS, DO and MM conceived and designed the study. YG, $\mathrm{MM}$ and AS collected the nodules and isolated the worms. EL and CM performed DNA extraction, the PCRs and the sequencing analysis. RL and DO performed microscope examinations. AS drafted the manuscript. All authors read and approved the final manuscript.

\section{References}

1. Al-Rawashdeh OF, Al-Ani FK, Sharrif LA, Al-Qudah KM, AlHami Y, Frank N. 2000. A survey of camel (Camelus dromedarius) diseases in Jordan. Journal of Zoo and Wildlife Medicine, 31(3), 335-338.

2. Anvari Tafti MH, Sazmand A, Hekmatimoghaddam S, Moobedi I. 2015. Prevalence and pathology of Onchocerca infection in camels (Camelus dromedarius) in central parts of Iran. Iranian Journal of Veterinary Medicine, 9(4), 257-261.

3. Awad MA, Osheik AA, Tageldin MH, Zakia AM. 1990. Note on Onchocerca armillata in the Sudanese camel (C. dromedarius). A histological and anatomo-pathological approach. Revue d'Élevage et de Médecine Vétérinaire des Pays Tropicaux, 43(3), 345-348.

4. Badanine NV. 1938. Sur la question d'helminthofaune du chameau en Turkmenie. Livro Jubilar do Professor Lauro Travassos, Rio de Janeiro, Brasil, 3, 61-73.

5. Bain O. 1975. Redescription de cinq espèces d'onchocerques. Annales de Parasitologie Humaine et Comparée, 50(6), 763-788.

6. Bain O. 1981. Le genre Onchocerca: hypothèses sur son évolution et clé dichotomique des espèces. Annales de Parasitologie Humaine et Comparée, 56(5), 503-526.

7. Bain O, Muller R, Khamis Y, Guilhon J, Van Veen TS. 1976. Onchocerca raillieti n. sp. (Filarioidea) chez l'Ane domestique en Afrique. Journal of Helminthology, 50(4), 287-293.

8. Bain O, Nasher K. 1981. Redescription de l'onchocerque du dromadaire, O. fasciata R. et H., 1910. Annales de Parasitologie Humaine et Comparée, 56(4), 401-406.

9. Banaja AA, Ghandour AM. 1994. A review of parasites of camels (Camelus dromedarius) in Saudi Arabia. Journal of King Abdulaziz University, 6, 75-86.

10. Chabaud AG, Bain O. 1994. The evolutionary expansion of the Spirurida. International Journal for Parasitology, 24(8), 11791201.

11. Cheema AH, El-Bihari S, Ashour NA, Ali AS. 1984. Onchocerciasis in camels (Camelus dromedarius) in Saudi Arabia. Journal of Helminthology, 58(4), 279-285.

12. Dakkak A, Ouhelli H. 1987. Helminths and helminthoses of the dromedary. A review of the literature. Revue Scientifique et Technique (International Office of Epizootics), 4(1), 447-461. 
13. Determann A, Mehlhorn H, Ghaffar FA. 1997. Electron microscope observations on Onchocerca ochengi and $O$. fasciata (Nematoda: Filarioidea). Parasitology Research, 83(6), 591-603.

14. El-Massry AA, Derbala AA. 2000. Evidence of Onchocerca fasciata (Filarioidea: Onchocercidae) in camels (Camelus dromedarius): I-prevalence, nodular lesions appearance and parasite morphology. Veterinary Parasitology, 88(3-4), 305-312.

15. El-Sinnary K, Hussein HS. 1981. Onchocerca gutturosa (Neumann) in camels (Camelus dromedarius) in the Sudan. Annals of Tropical Medicine and Hygiene, 75(4), 469-470.

16. Ferri E, Barbuto M, Bain O, Galimberti A, Uni S, Guerrero R, Ferté H, Bandi C, Martin C, Casiraghi M. 2009. Integrated taxonomy: traditional approach and DNA barcoding for the identification of filarioid worms and related parasites (Nematoda). Frontiers in Zoology, 6, 1 .

17. Food and Agriculture Organization of the United Nations. 2018. FAOSTAT - Food and agriculture organization of the united nations statistics division. FAO: Rome, Italy.

18. Ghandour A, Al-Amoudi A, Banaja A. 1991. Onchocerca fasciata Railliet and Henry, 1910 and its nodule development in camels in Saudi Arabia. Veterinary Parasitology, 39(1-2), 67-77.

19. Henry A, Masson G. 1933. Onchocercose cervicale du dromadaire. Bulletin de l'Académie Vétérinaire de France, 6(5), 208-213.

20. Holdsworth PA, Moorhouse DE. 1985. Onchocerca gutturosa in an Australian camel. Australian Veterinary Journal, 62(6), 201-202.

21. Hussein HS, Atta El Mannan AM, El Sinnary K. 1988. Onchocerca armillata Railliet and Henry, 1909 and Onchocerca gutturosa (Neumann, 1910) in camels (Camelus dromedarius L.) in the Sudan. Veterinary Research Communications, 12(6), 475-480.

22. Katoh K, Toh H. 2008. Recent developments in the MAFFT multiple sequence alignment program. Briefings in Bioinformatics, 9(4), 286-298.

23. Krueger A, Fischer P, Morales-Hojas R. 2007. Molecular phylogeny of the filaria genus Onchocerca with special emphasis on Afrotropical human and bovine parasites. Acta Tropica, 101(1), 1-14.

24. Lefoulon E, Bain O, Bourret J, Junker K, Guerrero R, Cañizales I, Kuzmin Y, Satoto TBT, Cardenas-Callirgos JM, de Souza Lima S, Raccurt C, Mutafchiev Y, Gavotte L, Martin C. 2015. Shaking the tree: multi-locus sequence typing usurps current Onchocercid (Filarial Nematode) phylogeny. PLoS Neglected Tropical Diseases, 9(11), e0004233.

25. Lefoulon E, Giannelli A, Makepeace BL, Mutafchiev Y, Townson S, Uni S, Verocai GG, Otranto D, Martin C. 2017. Whence river blindness? The domestication of mammals and host-parasite co-evolution in the nematode genus Onchocerca. International Journal for Parasitology, 47(8), 457-470.

26. Megersa B. 2010. An epidemiological study of major camel diseases in the Borana lowland, Southern Ethiopia. Oslo: Drylands Coordination Group.

27. Muller R. 1979. Identification of Onchocerca, in Symposia of the British Society for Parasitology, Vol. 17, in Problems in the Identification of Parasites and their Vectors, Taylor AER, Mullers R, Editors. Blackwell Scientific: London.p. 175-206.

28. Nana-Djeunga HC, Bourguinat C, Pion SD, Bopda J, Kengne-Ouafo JA, Njiokou F, Prichard RK, Wanji S, Kamgno J, Boussinesq M. 2014. Reproductive status of Onchocerca volvulus after ivermectin treatment in an ivermectin-naïve and a frequently treated population from Cameroon. PLoS Neglected Tropical Diseases, 8(4), e2824.

29. Nasher AK. 1986. Incidence and intensity of Onchocerca fasciata Railliet and Henry, 1910 in local camels in Saudi
Arabia. Annales de Parasitologie Humaine et Comparée, 61(1), 77-80.

30. Omar MS, Raoof AM. 1994. Histochemical distribution of hydrolytic enzymes in adult Onchocerca fasciata (Filarioidea: Onchocercidae). Parasitology Research, 80(3), 216-222.

31. Omar MS, Raoof AM, Al-Amari OM. 1996. Onchocerca fasciata: enzyme histochemistry and tissue distribution of various dehydrogenases in the adult female worm. Parasitology Research, 82(1), 32-37.

32. Orihel TC, Eberhard ML. 1998. Zoonotic filariasis. Clinical Microbiology Reviews, 11(2), 366-381.

33. Orlando L. 2016. Back to the roots and routes of dromedary domestication. Proceedings of the National Academy of Sciences, 113(24), 6588-6590.

34. Otranto D, Eberhard ML. 2011. Zoonotic helminths affecting the human eye. Parasites \& Vectors, 4(1), 41

35. Posada D. 2008. JModelTest: phylogenetic model averaging. Molecular Biology and Evolution, 25(7), 1253-1256.

36. Railliet A, Henry A. 1910. Les Onchocerques, Nématodes parasites du tissu conjonctif. Comptes Rendus des Séances de la Société de Biologie et de ses Filiales, 68, 248-251.

37. Ronquist F, Huelsenbeck JP. 2003. MrBayes 3: Bayesian phylogenetic inference under mixed models. Bioinformatics, 19(12), 1572-1574.

38. Round M. 1962. The helminth parasites of domesticated animals in Kenya. Journal of Helminthology, 36(4), 375-449.

39. Sazmand A, Anvari Tafti MH, Hekmatimoghaddam S, Moobedi I. 2013. Dipetalonema evansi infection in camels of Iran's central area. Pakistan Journal of Biological Sciences, 16(13), 647-650.

40. Sazmand A, Eigner B, Mirzaei M, Hekmatimoghaddam S, Harl J, Duscher GG, Fuehrer H-P, Joachim A. 2016. Molecular identification and phylogenetic analysis of Dipetalonema evansi (LEWIS, 1882) in camels (Camelus dromedarius) of Iran. Parasitology Research, 115(4), 1605-1610.

41. Sazmand A, Joachim A. 2017. Parasitic diseases of camels in Iran (1931-2017) - a literature review. Parasite, 24, 21.

42. Schillhorn-Van-Veen TW, Bello SI, Folaranmi DO. 1976. Onchocerca armillata (Railliet and Henry, 1909) from a new host, Camelus dromedari. Revue d'Élevage et de Médecine Vétérinaire des Pays Tropicaux, 29(3), 227-228.

43. Tamura K, Peterson D, Peterson N, Stecher G, Nei M, Kumar S. 2011. MEGA5: Molecular Evolutionary Genetics Analysis using maximum likelihood, evolutionary distance, and maximum parsimony methods. Molecular Biology and Evolution, 28, 2731-2739.

44. Uni S, Bain O, Takaoka H, Miyshita M, Suziki Y. 2001. Onchocerca dewittei japonica n. subsp., a common parasite from wild in Kyushu Island, Japan. Parasite, 8(3), 215-222.

45. Uni S, Fukuda M, Otsuka Y, Hiramatsu N, Yokobayashi K, Takahashi H, Murata S, Kusatake K, Morita E, Maruyama H, Hasegawa H, Shiwaku K, Ramli R, Azirun M, Takaoka H. 2015. New zoonotic cases of Onchocerca dewittei japonica (Nematoda: Onchocercidae) in Honshu, Japan. Parasites \& Vectors, 8(1), 59.

46. Yang XY, Luo XP, Yang LR, Wang R, Liu XY, Li JY. 2012. Onchocerca fasciata $18 \mathrm{~S}$ ribosomal RNA gene, partial sequence; internal transcribed spacer 1, 5.8S ribosomal RNA gene, and internal transcribed spacer 2, complete sequence; and $28 \mathrm{~S}$ ribosomal RNA gene, partial sequence. Genbank Accession Number: JQ316671.1. Available from: https:// www.ncbi.nlm.nih.gov/nuccore/JQ316671.1.

47. Yang XY, Luo XP, Yang LR, Wang R. Onchocerca fasciata cytochrome oxidase subunit I gene, partial cds; mitochondrial. GenBank Accession Number: JQ316672.1. Available from: https://www.ncbi.nlm.nih.gov/nuccore/JQ316672.1. 
Cite this article as: Mirzaei M, Ghahvei Y, Lefoulon E, Paolo Lia R, Otranto D, Martin C \& Sazmand A. 2018. Morphological and molecular characterization of Onchocerca fasciata (Nematoda, Onchocercidae) from dromedary camels (Camelus dromedarius) in Iran. Parasite 25, 50 .

\section{- PARASTE}

An international open-access, peer-reviewed, online journal publishing high quality papers on all aspects of human and animal parasitology

Reviews, articles and short notes may be submitted. Fields include, but are not limited to: general, medical and veterinary parasitology; morphology, including ultrastructure; parasite systematics, including entomology, acarology, helminthology and protistology, and molecular analyses; molecular biology and biochemistry; immunology of parasitic diseases; host-parasite relationships; ecology and life history of parasites; epidemiology; therapeutics; new diagnostic tools.

All papers in Parasite are published in English. Manuscripts should have a broad interest and must not have been published or submitted elsewhere. No limit is imposed on the length of manuscripts.

Parasite (open-access) continues Parasite (print and online editions, 1994-2012) and Annales de Parasitologie Humaine et Comparée (1923-1993) and is the official journal of the Société Française de Parasitologie. 